\title{
Policy Design and Implementation Issues of Regulating Greenhouse Gas Emissions in China
}

\author{
Xiangsheng Dou, Jingjing Xie, and Zenglong Ye
}

\begin{abstract}
The basic policy tools to regulate greenhouse gas emissions are the carbon taxes and the carbon emissions right trading. In theory, they have equivalents in the efficiency and effectiveness of carbon emissions reduction. However, due to the uncertainty of real world, so they no longer have theoretical equivalent, but difference. Therefore, it is necessary on the basis of the reality of socio-economic development and changes to choice and implement the most effective policy instruments. In the selection and design of specific policies, the diversification, stability and dynamic adjustment of policy objectives, the balance and coordination between international policies, as well as the interaction and coordination between different polices, should fully be considered.
\end{abstract}

Index Terms-Greenhouse gas emissions, policy instruments, carbon tax, carbon emissions right trading, uncertainty.

\section{INTRODUCTION}

The key to whether the targets of greenhouse gas emissions reduction could be achieved is how to design and implement reasonable and effective emissions reduction policies. From the aspect of policy instrument to view, the main policy tools to reduce greenhouse gas emissions have direct control, environmental responsibility, carbon tax (or eco-tax) and carbon (or greenhouse gas) emissions right trading. Among them, the latter two policy instruments are more often used, for relatively speaking they are built on the basis of market mechanism and more flexibly used, and have relatively low cost of implementation [1].

Of course, although both of carbon taxes and emissions trading are built on the basis of market mechanism and there are some similarities between them, and furthermore in the case of uncertainty their efficiency and effectiveness is theoretical equivalence [2],[3]. However, in practice, the degree that they are attached great importance and applied is different. Since the Kyoto Protocol, the carbon taxes have been widely used in many countries. However, the application of carbon emissions trading is still at the exploratory stage. To find out its cause deeply, it is likely related to the different characteristics of both and the different policy preference of the government. In fact, although the carbon tax policy has been widely used in many countries around the world, yet the carbon emissions right trading has aroused greater interest of the government and the

Manuscript received October 10, 2012; revised March 4, 2013. This work was supported by the National Social Science Foundation of China under Grant 10XJY004.

The authors are with the Center for International Economic Research, School of Public Administration, Southwest Jiaotong University, China (e-mail: douxiangsheng@tsinghua.org.cn, 1013964010@qq.com, 824590140@qq.com). practice and theory circles [1].

From the existing research literature to view, the respective merits about carbon taxes and carbon emissions trading have been a debate. The focus of debate, besides focusing on the transaction costs, welfare effects, policy environment and political risk, still involves in the personal preference, uncertainty, emissions measure, balance and coordination of the interests, and so on. It is generally believed that the carbon tax is easy to be implemented, and its tax revenue can be used for the personal distribution, and thus personal acceptability is relatively higher [3],[4]. However, the others believe that the carbon emissions right trading has more advantage, for it has many of advantages over cost-effectiveness, broad participation, fairness and equity between different countries, and being favor to control cumulative emissions. Relatively speaking, the carbon tax in these areas is inadequate [5],[6].

In fact, from the practice angle to view, the efficiency and effectiveness of two policy tools of carbon tax and carbon emissions right trading is closely related to the uncertainty of real socio-economic development. For example, the implementation of carbon tax needs the government to accurately calculate the balance and optimal tax rate, and to make dynamical adjustment timely in the light of changes in carbon emissions, but it is actually difficult to be done. Similarly, the implementation of carbon emissions trading is built on the basis of reasonable initial allocation of carbon emissions rights and the design of effective trading system, but this idealized environmental condition is usually very difficult to be fully equipped. Therefore, in this sense, both of carbon tax and carbon emissions right trading don't necessarily yield positive results [7].

Visibly, which policy is actually better, depending on a variety of factors, and it is difficult to make simple assumption. The best option is that, based on the reality of socio-economic development, both are used with their organically combined form, in order to give full play to the advantages of both. This paper will focus on these issues.

\section{A COMPARISON OF CARBON TAX AND CARBON EMISSIONS RIGHT TRADING}

Generally speaking, both of carbon tax and carbon emissions right trading are market-based environmental policy tools, for they guide the reduction of carbon emissions and the cut of external costs through price signals. The theoretical basis of carbon tax is the Pigou's tax thinking, and it is by the mandatory implementation of the Pigou's tax to increase the private cost of emissions, and thereby correcting the deviation of private costs from social costs, to reduce the 
loss of social welfare and improve the social welfare effects. However, the theoretical basis of the carbon emissions trading is the Coase theorem, and it achieves the internalization of the external costs through voluntary market transactions for carbon emissions rights, to achieve the purpose of correcting the deviation of private costs from the social costs [1].

However, on the formation mechanism of price signals, carbon taxes and carbon emissions trading are clearly different. The carbon tax is a centralized administrative behavior, and the implementation of mandatory carbon tax can effectively raise the private costs of emissions, to achieve the objective of emissions reduction. Therefore, the carbon tax has direct effect on price signal, and it is by direct impact on the costs and further the price of emissions to play a role. Different from carbon tax, carbon emissions right trading directly affects the amount of carbon emissions, it is through decentralized carbon emissions trading market to regulate the supply and demand of carbon emissions rights, and thus through carbon market mechanisms to form a balanced number and price of emissions. Once the equilibrium price signal of emissions right trading is formed, it can lead the emissions behavior of related entities to achieve the objective of emissions reduction [3].

Theoretically, in a world of certainty, if all conditions can be met, then carbon tax and emissions right trading have theoretically equivalent. If the related information that the government imposes a carbon tax is sufficient and there is no any rent-seeking and other improper behavior, as long as tax rate and tax base are appropriate, and the generation and use of tax revenues can be used for distribution purpose, then the carbon tax has environmental safety and cost-effectiveness. As for carbon emissions trading, If carbon emissions trading market is effective and the service system of carbon emissions trading is perfect, as long as the initial allocation of carbon emissions rights is reasonable and can adapt to the socio-economic changes, then the carbon emissions trading has environmental safety and cost effectiveness, too [3].

\begin{tabular}{|c|c|c|}
\hline Item & Carbon tax & Carbon emissions trading \\
\hline Opportunity costs & $\begin{array}{l}\text { Higher emissions measure and adaptable adjustment costs and } \\
\text { lower short-run costs. }\end{array}$ & $\begin{array}{l}\text { Higher administration and management costs, and lower } \\
\text { long-run and innovative costs. }\end{array}$ \\
\hline $\begin{array}{l}\text { Environmental } \\
\text { safety }\end{array}$ & $\begin{array}{l}\text { The dependence on uncertainty degrees of emissions, emissions } \\
\text { reduction costs, and equilibrium state. }\end{array}$ & $\begin{array}{l}\text { The dependence on uncertainty degrees of emissions, emissions } \\
\text { reduction costs, and equilibrium state. }\end{array}$ \\
\hline Participation degree & Limited participation & Broad participation \\
\hline Scope of coverage & Mainly applied to consumer products & Applied to all products \\
\hline Acceptability & $\begin{array}{l}\text { The dependence on the personal preference, and the use and } \\
\text { distribution of tax revenues. }\end{array}$ & $\begin{array}{l}\text { The dependence on the welfare effects, political acceptability, } \\
\text { and equity in the international context. }\end{array}$ \\
\hline $\begin{array}{l}\text { Administration and } \\
\text { management costs }\end{array}$ & $\begin{array}{l}\text { The carbon tax may more easily be implemented and the } \\
\text { revenues may be used for distribution, and thus the } \\
\text { administration and management costs are relatively lower. }\end{array}$ & $\begin{array}{l}\text { The administration and management costs can be higher } \\
\text { compared to the carbon taxes under multiple natural and } \\
\text { human-related uncertainties. }\end{array}$ \\
\hline $\begin{array}{l}\text { Implementation } \\
\text { condition }\end{array}$ & $\begin{array}{l}\text { The dependence on the gain of information, emissions measure, } \\
\text { effective implementation, and compliance costs. }\end{array}$ & $\begin{array}{l}\text { The dependence on the design of trading scheme, the initial } \\
\text { permit allocation, the regulation and adjustment, the market } \\
\text { operation, and the personal account management, etc. }\end{array}$ \\
\hline Equity & Inequity in the international context. & Equity in the international context. \\
\hline $\begin{array}{l}\text { Complexity of } \\
\text { scheme design }\end{array}$ & Relatively simple & Relatively complex \\
\hline $\begin{array}{l}\text { Function and } \\
\text { properties }\end{array}$ & $\begin{array}{l}\text { To fix the price of emissions, where there is uncertainty over the } \\
\text { cost function. }\end{array}$ & $\begin{array}{l}\text { To fix the quantity of emissions, where there is uncertainty over } \\
\text { the damage function. }\end{array}$ \\
\hline $\begin{array}{l}\text { Efficiency and } \\
\text { effectiveness }\end{array}$ & $\begin{array}{l}\text { Being theoretically equivalent, but in practice more effective in } \\
\text { the short-run }\end{array}$ & $\begin{array}{l}\text { Being theoretically equivalent, but in practice more effective in } \\
\text { the long-run. }\end{array}$ \\
\hline $\begin{array}{l}\text { Policy enforcement } \\
\text { mechanism }\end{array}$ & Centralized command-and-control methods & Decentralized market simulation schemes \\
\hline
\end{tabular}

However, in the real world, the certainty is just a chance, and the uncertainty is norm. Therefore, the carbon tax and the carbon emissions right trading have usually no longer theoretical equivalent, and which is better, depending on the reality of socio-economic conditions. Generally speaking, the implementation of carbon tax is relatively simple, but the most basic requirement of its implementation is that it needs the government to grasp full information of emissions and reduction costs. However, due to the natural and man-made uncertainty, the government is actually impossible to obtain adequate information, which affects the efficiency and effectiveness of the implementation of the policy of carbon tax. Unlike the carbon tax, the carbon emissions right trading involves the rational allocation of initial carbon emissions rights, the effectiveness of carbon emissions trading market and the reasonable design of trading system and on these aspects there is also a lot of uncertainty, so this limits the efficiency and effectiveness of its implementation, too. From a practical point of view, in short, the carbon tax may be a better choice; while in the long-term, the carbon emissions 
right trading may be a better choice [3],[7].

From the conditions and the complexity of policy design and implementation to view, there are differences between the carbon tax and the carbon emissions right trading. Generally speaking, the process of the implementation of carbon tax is relatively simple, but in the decision of optimal equilibrium tax rate and tax base there is uncertainty, mainly for there is the problem of measure of carbon emissions and its change, which in turn may cause systemic risks to the implementation of carbon tax. At the same time, in the context of globalization, the carbon tax is difficult to achieve the balance and co-ordination between the different countries, which is obviously not conducive to the cooperation of international environment. In contrast, for the carbon emissions right trading, because it involves in the rational allocation of initial carbon emissions rights, the establishment of carbon emissions trading market and the design of related trading system and rules, so its implementation process is relatively more complex. However, once a good trading regime has been formed, then the trading can rely on market mechanism itself to make adaptive regulation, to diversify the risk of policy. Especially, the carbon emissions right trading is conducive to achieving a balance and co-ordination between different countries, which helps to promote international environmental cooperation [8].

In a word, the carbon tax and the carbon emissions right trading have significant differences in many aspects, and Table I makes more comprehensive comparison for both from the fourteen different aspects of opportunity costs, environmental security and others. As can be seen from Table I, in fact, from a theoretical point of view, both have their own strengths and weaknesses, respectively. However, from low carbon policy practice around the world to see, what low carbon policy is actually selected often depends on the policy tradition and preferences. In the developing countries of immature market mechanism, the carbon tax is often more preferred; while in the developed countries with mature market mechanism, the carbon emissions right trading is often more inclined. Of course, overall speaking, at this stage the carbon tax and the carbon emissions trading are often used by different countries, and have achieved certain effect, too.

\section{Policy Choice and Design of Regulating China's GREENHOUSE GAS EMISSIONS}

From the perspective of policy options, in the choice of greenhouse gas emissions policy, China must at least consider the following issues:

1) How in the premise of ensuring rapid and sustainable development of socio-economy to achieve the emissions reduction targets? This is a very challenging task. Because the socio-economic development will inevitably increase total emissions, it will increase the difficulty of emissions cut.

2) Because there is serious imbalance of development between China's different regions, so in the process of policy implementation it is still necessary to take into account the interests of different regions, which has an adverse impact on the effectiveness of the implementation of overall policy.

3) How to reasonably design and use the carbon tax policy? Because the prerequisite and basis of the application of carbon tax is accurate measure for carbon emissions and its dynamic change, only accurately to measure out the scale of carbon emissions, the optimal equilibrium tax rate and tax base can be designed to achieve the goals of environmental safety and cost effectiveness, but in fact this is difficult to do.

4) At this stage, China's market system is not still perfect. Especially, the carbon emissions trading and carbon financial system is still at its early stage of development, which will severely hamper the implementation of the policy of carbon emissions right trading.

In view of above reasons, at this stage the selection and design of the policy of China's greenhouse gas emissions must first consider the diversification of policy objectives. In many goals, the first and foremost is to take into account both the socio-economic development and the environmental protection. It is neither able to promote socio-economic development at the expense of sacrificing the environment, nor to ignore the socio-economic development to implement environmental protection policies, which is the basic starting point of the selection and design of greenhouse gas emissions policy. Associated with this, being the problems of the equilibrium between different regions, the equilibrium between different industries and the coordination and implementation between different industrial chains in the same industry, are necessarily be considered important issues in the choice and design of policy, too. Secondly, the conflict and coordination problems of the interests between different economic entities must be considered. Because whether a policy can be effectively implemented or not is built on the basis of public acceptability, the optimal policy choice and design must be the policy that most actors are able to accept [3]. If not so, it will certainly add policy implementation costs, and even lead to the failure of the policy. Obviously, any single policy is difficult to solve above problems, only to reasonably mix and match two different emissions reduction policies of the carbon tax and the emissions trading policies, can the policy goals be achieved. Of course, how to distribute each policy to the objective of its strongest force, so as to play the best effect for different policy mix and match, is also one of the problems that must be addressed in the choice and design of policy, for it is decided by many of factors.

In the selection and design of carbon emissions reduction policies, the stability and dynamic adjustment of the policy must also taken into account. The meaning to maintain policy stability is that it may reasonably change and guide the expectation of actors, and thus to enhance the initiative and enthusiasm consciously participating in emissions reduction, which is particularly important in the short term. Timely to make the dynamic adjustment of policy is the requirement of socio-economic development as well as the inevitable requirement of environment quality increasingly improved. Especially in the long-term, if the dynamic adjustment of policy is not timely made in the light of the reality of social and economic development and changes, then it will seriously worsen the effect of emissions reduction policies, 
and to make the emission reduction policies to lose their role. However, from their respective policy features of the carbon taxes and the carbon emissions trading to view, the carbon tax is relatively stable, so it has a strong short-term effect of emissions reduction. However, the carbon emissions trading more shows its dynamic changes and strong adaptability and its stability is relatively weak, but it seems to have a stronger role in the long-term accumulation control of carbon emissions. In this regard the role of the carbon tax is relatively weak. This also proves that the two policies of the carbon tax and the emissions trading need to be mixed and matched applications. Of course, the environmental conditions of the implementations of different policies are different, while the environmental conditions of policy may be artificially created, so it creates a larger space for the choice and design of different policies.

The difficulty of the option and design of emissions reduction policy is that there is a lot of uncertainty in reality. It is just because of a variety of internal and external uncertainties, making the emissions reduction policy to be seriously concerned. In fact, both the carbon tax and the carbon emissions right trading can only in certain conditions show the best efficiency and effectiveness. If there is natural and man-made uncertainty, then they have not the environmental safety and cost-effectiveness [8]. From the case of real socio-economic and environmental changes to view, the different economic sectors and actors for their own interests at least would rather hide their emissions and emissions reduction cost information, in addition to the uncertainty of natural and environmental change, this makes it is impossible to select and design the optimal policy. Therefore, in the reality, the compromise policy accepted by most people is often taken.

In the context of globalization, the international balance and coordination problems in the selection and design of emissions reduction policies should be considered, too. Because the climate problem is a global problem, no any single country alone can solve it. Therefore, it is necessary in international environmental cooperation framework to select and design emissions reduction policies. From the emissions reduction policy itself to view, due to different tax system, the balance and coordination capability of carbon tax between the different countries is relatively weak, but the carbon emissions right trading has strong balance and coordination capability between different countries [8]. China is a great developing country, If China hopes to obtain a dominant position in the game of international talk in the future, it is necessary from an international perspective to choose and design emissions reduction policies to obtain the right of speaking in the international community.

In addition, the selection and design of emissions reduction policies is still related to the interaction and coordination between different policies, and it is one of effective measures to deal with the problem of uncertainty in different circumstances. In practice, no any country in the world really implements single policy tool. In fact, it is impossible for any single policy tool to have the absolute advantage. If the various policies can be coordinated from the perspective of overall situation, then it is possible to make all policies to play greater effectiveness.

\section{The ImPlementation IsSUES OF Two POLICY} INSTRUMENTS UNDER THE CONDITION OF CHINA'S REALITY

In view of the complexity of real problems, in the process of specific implementation of policy, firstly it is necessary to establish the policy goal of greenhouse gas emissions reduction in the light of the conditions of reality and overall socio-economic development strategy. Because the policy objectives are the premise and basis of policy option, design and implementation, only to establish scientific and rational policy objectives, can the correctness of policy tool selection and the effectiveness of policy implementation be ensured. The key to the establishment of scientific and rational policy objectives is to make the selection and implementation of policy to adequately reflect the objective reality of socio-economic development. If the policy target is too high, it may affect the normal development of socio-economy. In turn, if the policy target is too low, it is difficult to obtain the ideal effect of policy.

The establishment of scientific and reasonable emissions reduction policy objectives needs also take into account overall planning and coordination problem between short-term and long-term policy objectives. Generally, the long-term policy objective has balanced and optimal property, but the short-term policy objective more tends to deviate from equilibrium and optimality, which is decided by the complexity of socio-economic system and the limitation of the understanding of policy decision-makers. Therefore, the short-term and the long-term policy goals are often not entirely consistent, and sometimes may appear serious deviation from the long term. However, in a long run, both are exactly the same. Of course, even in the short term, the short-term policy objectives should be compatible and coordination with the long-term policy objectives as much as possible, which is conducive to reducing the appearance of jumping and intermittent imbalances, to enhance the continuity and effectiveness of policy.

Another important aspect of the implementation of emissions reduction policies is that it is necessary to make the monitoring on the policy implementation process and the scientific evaluation and analysis on the effects of policy implementation, in order timely to find the problem and correct the errors in policy implementation, thereby improving the efficiency and effectiveness of policy implementation. It is particularly important for emissions reduction policies. Because at present the implementation of China's greenhouse gas emissions reduction policies is at the exploratory stage, and in many aspects successful experience is lacking, so both on the choice and design of policies and on specific implementation of policies have a lot of uncertainty. In this case, overall to strengthen monitoring on the policy implementation process and the assessment of policy effects is very necessary.

The biggest challenge of the implementation of emissions reduction policies at this stage is how to properly deal with the relationship between the administrative role and the market mechanism role. Although under the conditions of 
market economy all policy instruments and measures taking the carbon tax and the carbon emissions right trading as the representative must be established on the basis of market mechanism, yet in fact the carbon tax more depends on the executive power including the determination of carbon tax rate and tax base as well as the collection and use of carbon tax. Therefore, all are executed by the government-led way, and the role of market mechanism is smaller here. Unlike the carbon tax, although the carbon emissions right trading is also inseparable from the intervention and support of the administration, yet here the role of market mechanism has been played in a greater degree. Theoretically, compared with the administrative manner, the role of market-oriented manner may be more efficient. However, the role of market mechanism is built on the basis of perfect market system. Because China's market system is not perfect at this stage, it restricts the efficiency and effectiveness of carbon emissions right trading policy. In contrast, because of the relatively high efficiency of administrative means, at least at this stage the efficiency and effectiveness of carbon tax may be better. Therefore, overall speaking, in specific context of China at this stage, China may first try the interim emissions reduction policies, for example, to carry out emissions reduction activities mainly by way of carbon tax policy. At the same time, it is necessary actively to create conditions for carbon emissions right trading and timely to promote it in the manner of trying and demonstration, and when the conditions are ripe, again timely to realize the transition from the administration-orientation to the market-orientation [9].

Of course, the policy implementation of both the carbon tax and the carbon emissions right trading requires favorable policy environment and conditions. For the carbon tax, the implementation of carbon tax need to gather more information about the function of emissions scale, emissions reduction costs and implementation costs. The relevant government and department only obtains sufficient information, then an optimal tax mechanism can be designed, and thereby enhancing the acceptability and implementation effects of the carbon tax. Therefore, it is necessary to establish sound measure and assessment agencies, to provide the necessary information and other services for the implementation of carbon tax.

As for the trading policy of carbon emissions rights, because its implementation involves many aspects such as the allocation of initial carbon emissions rights, the construction of trading platform, the service system building of trading, the formulation of trading rules and the others, so the building of optimal trading mechanism is very complex, which is one of the most basic causes that many countries prefer the carbon tax policy. However, because the carbon emissions right trading has a wide range of adaptability and flexibility, so it is bound to be more and more valued in the future. In fact, the European Union, the United States, the Japan and many other countries in the world are positively developing the carbon emissions right trading market, in order to gain the initiative and greater benefits in the future global carbon emissions trading [10]. Therefore, China must fully draw successful experience from foreign countries, and accelerate the construction of carbon emissions right trading system and platform, so as to create good conditions for full implementation of carbon emissions right trading [11].

\section{CONCLUSION}

In a world of certainty, the carbon tax and the carbon emissions right trading have theoretical equivalence in the efficiency and effectiveness of carbon emissions reduction. However, in the real world there is a lot of uncertainty, and in this case they have no longer the theoretical equivalent. Therefore, how to select and implement the most effective policy instruments of emissions reduction based on the reality of socio-economic development and changes, is direct related to the effect and the success or failure of the implementation of carbon emissions reduction policies.

In the selection of greenhouse gas emissions reduction policies, it is necessary to respect the objective reality of China's socio-economic development. Firstly, it is necessary to consider the diversity of policy objectives. Secondly, the stability and dynamic adjustment of policy must be taken into account. Again in the context of globalization, the international balance and coordination problems must be considered. In addition, the problem of the interaction and coordination between different policies must be considered, too. Only by this way, will it be possible to make a variety of different policies to play greater effectiveness.

\section{REFERENCES}

[1] E. Crals and L. Vereeck, "Taxes, tradable rights and transaction costs,"European Journal of Law and Economics, vol. 20, pp.199-223, 2005.

[2] M. L. Weitzman, "Price VS. quantities," Review of Economic Studies, vol. 41, pp. 477-491, 1974.

[3] A. L. Bristow, M. Wardman, A. M. Zanni, and P. K. Chintakayala, "Public acceptability of personal carbon trading and carbon tax," Ecological Economics, vol.69, pp. 1824-1837, 2010.

[4] R. A. Yonah and D. Uhlmann, "Combating global climate change: why a carbon tax is a better response to global warming than cap and trade," Stanford Environmental Law Journal, vol. 28, no. 3, 2009.

[5] N. Keohane, "Cap and trade, rehabilitated: using tradable permits to control U. S. greenhouse gases," Review of Environmental Economics and Policy, no. 3, pp. 1042-62, 2009.

[6] Y. Y. He, L. Z. Wang, and J. H. Wang, "Cap-and-trade vs. carbon taxes: A quantitative comparison from a generation expansion planning perspective," Computers \& Industrial Engineering, vol. 63, no. 3, pp. 708-716, 2012.

[7] T. Ermolieva, Y. Ermoliev, G. Fischer, M. Jonas, M. Makowski, and F. Wagner, "Carbon emission trading and carbon taxes under uncertainties," Climate Change, vol.103, pp. 277-289, 2010.

[8] W. Sterk and J. Kruger, "Establishing a transatlantic carbon market," Climate Policy, no. 9, pp. 389-401, 2009.

[9] M. Lockwood, "The economics of personal carbon trading," Climate Policy, no. 10, pp. 447-461, 2010.

[10] F. Carolyn, K. Suzi, and T. Michael, "Using emissions trading to regulate U.S. greenhouse gas emissions: An overview of policy design and implementation issues," National Tax Journal, vol. 51, no. 3, pp. 453-464, Sep. 1998.

[11] Q. Wang, H. Gao, F. S. Wen, I. MacGill, and J. S. Huang, "From command and control regulations to a business proposition: Creating a Chinese market for emissions trading," International Journal of Energy Sector Management, vol. 3, no. 1, pp. 62-82, 2009.

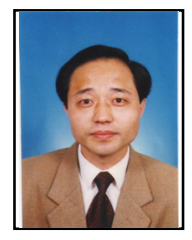

Xiangsheng Dou was born in Dingyuan County of Anhui Province in China on February 18, 1963. His educational background is that, from Sep., 1998 to July, 2001, studied as a graduate for a Ph.D. degree of economics in the department of economics, Xiamen University, Xiamen City, China. From 1991 to 1994, studied as a graduate for a master degree of economics in 
the department of agricultural economics, Renmin University of China, Beijing City, China. From 1982 to 1986, studied as an undergraduate for a bachelor degree of agricultural science in the department of animal science, Anhui University of Science and Technology, Chuzhou City, China. The author's major fields of study are the international economics, mathematic economics, and development economics, etc.

He has been worked in the Southwest Jiaotong University Since April, 2004 as a Professor of Economics, in Chengdu, P. R. China.

Prof. Dou is a referee of some journals such as the Renewable and Sustainable Energy Reviews, the Economic Modeling, and so on.

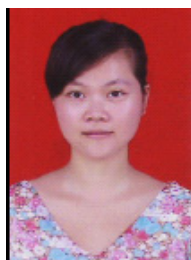

Jingjing Xie was born in Suizhou City of Hubei Province in China on Oct. 15, 1987. Her educational background is that, from Sep., 2007 to Jul., 2011, studied as an undergraduate for a bachelor degree of Science in the department of Mathematics and Applied Mathematics, China Three Gorges University, Yichang City, China.

She has been studied in the Southwest Jiaotong University since Sep., 2011 as a Master Candidate of World Economics, in Chengdu, China.

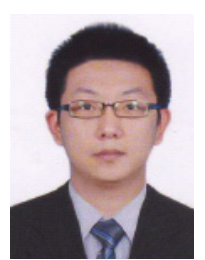

Zenglong Ye was born in Jilin City of Jilin Province in China on Jan. 18, 1989. His educational background is that, from Sep., 2008 to Jul., 2012, studied as an undergraduate for a bachelor degree of economics in the department of economics, Sichuan University, Chengdu City, China.

He has been studied in the Southwest Jiaotong University since Sep., 2012 as a Master Candidate of Theoretical Economics, in Chengdu, China. 